\title{
A ERA DA AFIRMAÇ̃̃O DOS DIREITOS DOS ANIMAIS NO CENÁRIO GLOBAL E SEU FUNDAMENTO NA SOLIDARIEDADE ENTRE ESPÉCIES
}

\author{
The age of affirmation of animals rights in global scenery and its reason of \\ solidarity between species
}

Recebido: 29.05.2018 | Aceito: 20.07.2018

\section{Lívia Gaigher Bósio Campello}

Pós-Doutorado em Direito do Estado pela Universidade de São Paulo - USP. Professora Permanente do Programa de Mestrado em Direitos Humanos da Universidade Federal de Mato Grosso do Sul - UFMS. Coordenadora do Programa de Mestrado em Direitos Humanos da UFMS. Professora responsável pelo Grupo de Pesquisa Direitos Humanos, Meio Ambiente e Desenvolvimento Sustentável Global da UFMS. Lattes: http://lattes.cnpq.br/9067637443861868. E-mail: liviagaigher@gmail.com.

\begin{abstract}
Ana Carolina Vieira de Barros
Graduada em Direito pela UFMS. Especialista em Direito de Família e Sucessões. Aluna especial do Mestrado em Direitos Humanos (UFMS) e integrante do Grupo de Pesquisa Direitos Humanos, Meio Ambiente e Desenvolvimento Sustentável Global da UFMS. Analista Judiciário do Tribunal de Justiça de Mato Grosso do Sul. Lattes: http:/ / lattes.cnpq. br/1427768714892686. E-mail: anacarolinavb@hotmail.com.
\end{abstract}

\begin{abstract}
Resumo
O objetivo deste trabalho é relatar os principais marcos dos Direitos dos Animais no contexto mundial, seguindo uma linha histórica e cronológica, bem como realizar a análise expositiva e crítica sobre a relação entre o Princípio da Solidariedade e essas latentes garantias. O tema do direito dos animais adentra o contexto social e incita reflexões sobre a necessidade dessas garantias serem discutidas nas pautas internacionais e nacionais, além do debate na sociedade civil e principalmente nas entidades acadêmicas. A era da inserção efetiva dos não-humanos em um contexto global requer regulamentação mundial e adoção de parâmetros para um tratamento animal consciente e digno. A metodologia usada para a construção de um panorama sobre a matéria é a pesquisa documental e bibliográfica, a partir do método dedutivo.
\end{abstract}

Palavras-chave: Princípio da Solidariedade; Direito Animal; Direito dos Não-humanos; Direito Ambiental.

\begin{abstract}
The aim of this work is to report the main milestones of animal rights in the world context, following a historical and chronological line, as well as conducting the expository and critical analysis of the relationship between the principle of solidarity and those latent Guarantees. The theme of animal law enterers the social context and encourages reflections on the need for these guarantees to be discussed in international and national tariffs, in addition to the debate in civil society and especially in academic institutions. The age of effective insertion of non-humans into a global context requires global regulation and adoption of parameters for a conscious and dignified animal treatment. The methodology used for the construction of a panorama on the subject is the documentary and bibliographic research, from the deductive method.
\end{abstract}


KeYwORDs: Principle of solidarity; Animal law; Non-human rights; Environmental law.

Sumário: Introdução. 1. A pauta internacional dos direitos dos animais. 2. A vida permeada pelo direito de solidariedade. 2.1 Breve caracterização dos direitos de solidariedade e integralidade dos princípios na esfera global. 2.2 A chegada dos direitos dos animais 3. Os não-humanos e a sociedade atual: construção da solidariedade. 3.1 Os desafios na tutela ambiental. 3.2 Novo panorama dos direitos dos animais. Conclusão. Referências.

\section{INTRODUÇÃo}

A interação do homem com a natureza, perpetrada pela utilização dos recursos naturais e animais, se torna, a cada dia, uma das pautas principais na agenda de debate entre os Estados. Dentro desse aspecto, a análise sobre os direitos atribuídos aos animais enquanto seres vivos e, sobremaneira, em suas relações com os humanos, ganha destaque no cenário global, ante ao surgimento de diversas questões que requerem a tutela jurídica e ainda não encontraram o respaldo do próprio Direito, dos governos e da comunidade global.

Ao lado disso, é importante que nessa fase em que as garantias animais estão se solidificando no cenário internacional que o pesquisador esteja apto a fazer uma compilação das convenções, documentos e entidades militantes na problemática, o que também se objetiva no presente trabalho, afinal, o encadeamento histórico e lógico do "direito ao bem estar animal" deve ser conhecido por todos.

No ano de 2018 a Declaração Universal dos Direitos dos Animais (1978) completa 40 (quarenta) anos e, embora este quadriênio tenha sido marcado por uma série de eventos que contribuíram para a evolução destes direitos na sociedade, ainda existem muitos questionamentos e persiste a necessidade de reafirmação dessas garantias por meio do constante debate. Aliado à questão, o homem passa a perceber que os direitos de solidariedade, os quais são responsáveis pela ligação de toda a comunidade global na salvaguarda dos direitos individuais e coletivos do ser humano, pode ajudar na defesa das prerrogativas existentes aos não-humanos, afirmando, assim, a solidariedade entre espécies.

Por fim, o objetivo adjacente desta pesquisa bibliográfica, descritiva e documental se concentra na reapresentação ao cenário jurídico e social dos direitos dos animais/não-humanos, sob o enfoque do princípio da solidariedade, na construção de um panorama de ajuda mútua entre as espécies. Assim, se intenta que a sociedade passe a ponderar e dirimir os conflitos existentes quanto aos direitos desses seres, de modo a estabelecer uma tutela animal digna, jurídica e sustentável, não somente no âmbito nacional ou regional e, sim, na órbita internacional. 


\section{A pauta internacional dos direitos dos animais}

Uma das perguntas centrais feita por Charlotte E. Blattner em seu artigo "Global Animal Law: Hope beyond Illusion: The Potential and Potential Limits of International Law in Regulating Animal Matters" é se o estado de bem-estar animal se tornou um bem global que requer uma regulação internacional (BLATTNER, 2015). Pela análise do texto mencionado, há o pensamento afirmativo tendo em vista que quando um assunto começa a ser discutido em âmbito mundial, a questão debatida passa a ser visualizada pelos Estados com maior solidez e de maneira criteriosa.

Quando os governos começam a assumir tais posturas perante a comunidade mundial normalmente se baseiam em documentos assinados pelos Estados, os quais firmam o reconhecimento quanto a determinado assunto e se forma o compromisso em sua proteção no cenário global e, por consequência, local. Igualmente ao Direito Ambiental, os Direitos dos Animais possuem sua base alicerçada em tais ferramentas, ou seja, em encontros internacionais entre as nações, sendo que tais reuniões são permeadas antes e depois por intensas argumentações que levam à adoção de políticas nacionais.

É necessário colocar em pauta que as convenções e documentos que aqui serão abordados foram fruto do incessante debate praticado por atores governamentais e não-governamentais. Aqueles são exemplificados pelos Estados e as organizações governamentais, enquanto estes são concentrados na comunidade científica, nas organizações não governamentais, na sociedade civil, nos grupos jurídicos, no setor corporativo/privado, nas comunidades indígenas e na mídia. (SANDS, 2003).

Nessa perspectiva, é relevante rever o conceito das organizações governamentais para melhor análise da conjuntura em pauta. Estas são criadas pelos grupos estatais, por meio de cooperação, com o fito de, conjuntamente, os governos se aliarem em busca de melhores condições sociais, políticas e econômicas. (Portal de pesquisas temáticas e educacionais, s.d.). Interessante mencionar que muitos desses entes são caracterizados como ramificações da Organização das Nações Unidas - ONU (por exemplo OMS (Organização Mundial da Saúde), OIT (Organização Internacional do Trabalho), OMC (Organização Mundial do Comércio), etc). Veja-se:

A natureza descentralizada das organizações internacionais no campo do meio ambiente torna difícil caracterizar o papel delas por qualquer critério, sejam estes funcionais, setoriais ou geográficos. Tais organizações podem ser divididas em três categorias gerais: organizações globais associadas com a Organização das Nações Unidas (ONU) e suas agências especializadas; organizações regionais fora do sistema da ONU; e as organizações firmadas por tratados de cunho ambiental ou outro. Entre essas categorias, com certeza, há sobreposições, uma vez que muitas dessas organizações referentes à terceira categoria foram criadas por atos da ONU ou de suas agências. (SANDS, 2003, p. 73)

A despeito dessas diferenciações entre esses atores, nota-se que cada vez mais se estabelece um cenário de construção e afirmação de garantias compostos por múltiplos atores, composição que cria o modelo multistakeholder, o qual ocorre quando diversos entes da sociedade se envolvem e participam ativamente do desenvolvimento de questões de interesse internacional. É o modelo de cooperação internacional a ser seguido futuramente, pois enseja o 
direito de participação e traz a noção de que não somente os atores governamentais possuem voz na discussão de temas relevantes.

Passada essa primeira observação quanto à caracterização dos atores internacionais, o leitor pode obter maior compreensão quanto à estruturação dos marcos relacionados à proteção ambiental e aos direitos dos animais. Nesse contexto, no ano de 1948, a União Internacional para a Conservação da Natureza e dos Seus Recursos (IUCN, em inglês), idealizada por Julian Huxley e Max Nicholson foi a "primeira organização voltada para a proteção da biodiversidade", a qual possui hoje 216 (duzentos e dezesseis) membros. (CAMATTA; SOUZA; ARRUDA JÚNIOR, 2014, p. 31). Nesse contexto, observa-se:

\begin{abstract}
Ela é uma das maiores autoridades sobre o ambiente e o desenvolvimento sustentável, sendo composta por mais de mil e duzentas organizações-membro, incluindo novecentas Organizações não Governamentais, onze mil cientistas (voluntários e especialistas) em quarenta e cinco escritórios divididos por todo o globo; um fórum neutro para os governos, as ONGs, os cientistas, empresas e comunidades locais para se encontrarem e buscar soluções práticas para os desafios de conservação e desenvolvimento; milhares de projetos de campo e atividades ao redor do mundo; governança por um Conselho eleito pelas organizações membros a cada quatro anos no Congresso Mundial de Conservação da UICN; financiada por governos, agências, fundações, organizações membros bilaterais e multilaterais e corporações; e, por fim, possui estatuto de observador oficial na Assembleia Geral das Nações Unidas (UICN) (...) No Brasil, a UICN tem sede em Brasília/DF desde agosto de 2010. (CAMATTA; SOUZA; ARRUDA JÚNIOR, 2014, p. 32).
\end{abstract}

Como se pode notar, o espectro de atuação da IUCN é amplo e além do debate frequente das questões naturais, a organização também se torna base intelectual para diversos movimentos e, principalmente, para as políticas estatais e ações adotadas por grupos da sociedade civil. No endereço eletrônico da organização (https://www.iucn.org/), o leitor consegue obter inúmeras informações relevantes não somente sobre a composição e funcionamento da IUCN. Mais do que isso, pode ter acesso a várias publicações sobre o tema, bem como visualizar a "lista vermelha dos ecossistemas ameaçados" e os relatórios anuais acerca da realidade dos ecossistemas nas diferentes regiões da Terra.

Não obstante, a IUCN realiza parcerias com outras entidades governamentais e não-governamentais para o alcance de seus objetivos, a exemplo do PNUMA (Programa das Nações Unidas para o Meio Ambiente), o qual foi estabelecido no ano de 1972 e é o responsável por centralizar as ações advindas do sistema das nações unidas no contexto do desenvolvimento sustentável na seara ambiental.

Em continuação, o ano de 1948 também foi palco para a Convenção Internacional para a Regulação da Atividade Baleeira (International Convention for the Regulation of Whaling), uma das primeiras convenções a inserir o debate sobre a questão animal no plano internacional, tendo criado uma comissão a fim de promover a proteção das baleias dentro do cenário exploratório. (BLATTNER, 2015, p. 24-25).

Não há como se esquecer, por outro lado, da mais antiga instituição europeia criada: o Conselho da Europa, o qual engloba a Convenção Europeia dos Direitos Humanos e o Tribunal Europeu dos Direitos Humanos, sendo composto por 47 (quarenta e sete) países. É 
por meio dessa associação que há a ampla abordagem de três principais grupos de animais domésticos: os animais do campo, os animais utilizados para pesquisa e os pet's ou animais de companhia. (BLATTNER, 2015, p. 28)

Após esse significativo "sopro" na proteção e estabelecimento das raízes da doutrina animal no planeta, a década de 1970 veio para confirmar o crescimento da "consciência animal" principalmente entre os intelectuais do assunto. Sobre essa fase, veja-se:

\begin{abstract}
Os tardios anos setenta marcaram a emergência do movimento dos direitos dos animais, o qual manteve a tradicional preocupação com o bem-estar animal, visualizando os animais como seres sensitivos que devem ser protegidos de crueldades desnecessárias. O movimento inseriu uma nova linguagem de direitos, como a base para as exigências do fim da exploração institucionalizada desses seres vivos (...) a teoria dos direitos dos animais prediz que até mesmo os não-humanos possuem direitos de certa maneira similares aos direitos dos seres humanos. Os direitos dos animais asseguram que relevantes interesses animais são absolutamente protegidos e não podem ser sacrificados até mesmo para beneficiar o homem, ou em situações em que os direitos em jogo desses animais devem ser explorados humanamente e sem sofrimento desnecessário. (FRANCIONE, 1996, p. 398)
\end{abstract}

Foi nesse momento que os movimentos relacionados aos direitos dos animais tiveram grande crescimento, vez que passou a se questionar até que ponto o progresso humano poderia seguir sem comprometer os recursos que seriam destinados às gerações posteriores. Essa arguição se desdobra em uma reflexão que tem como ponto principal o fato de que os animais, assim como os homens, possuem certo valor intrínseco, o qual deve ser respeitado independentemente das consequências para a sociedade, sem que sejam tratados como meros instrumentos. (FRANCIONE, 1996, p. 398)

Adiante, em 1973 foi estabelecida a Convenção sobre Comércio Internacional das Espécies da Flora e Fauna Selvagens em Perigo de Extinção (CITES), assinada hoje por 183 (cento e oitenta e três) países, a qual foi elaborada "para regular de forma eficaz o comércio de espécies da fauna e flora, prevenindo-as do perigo de extinção, quando a ameaça for o comércio internacional." Dessa forma, a convenção atribui "aos países produtores e consumidores sua parte na responsabilidade comum e estabelece mecanismos necessários para garantir a exploração não prejudicial das populações." (IBAMA, 2017).

Tal definição é corroborada pelos ensinamentos de Charlotte E. Blattner:

A CITES representa um dos acordos mais importantes, o qual foi especialmente idealizado para proteger os animais e expressar o valor deles como parte indispensável do sistema natural da terra, para a proteção da população presente e daquelas que virão $O$ objetivo da Convenção é acabar com a extinção. $O$ tratado e seus apêndices atualmente protegem mais de 5.600 espécies de animais, que são categorizados em três tipos de proteções, dependendo de seu nível de perigo. O gorila beringei, por exemplo, é considerado ameaçado de extinção e, portanto, é protegido pelo Apêndice I da Convenção, proporcionando o mais alto nível de proteção de todos os apêndices. (BLATTNER, 2015, pp. 25-26) 
Posteriormente, o cientista Georges Heuse propôs em 1978 a Declaração Universal dos Direitos dos Animais, a qual foi levada à UNESCO (Organização das Nações Unidas para a Educação, a Ciência e a Cultura) e possui o objetivo de servir como diploma legal em relação ao propósito animal para os países integrantes da ONU.

A luta pela salvaguarda de determinados grupos de animais, como os silvestres, foi mais tarde objeto de pauta das reuniões realizadas na Convenção de Bonn em 1979, a qual discutiu a conservação das espécies migratórias pertencentes à fauna selvagem. Na leitura dos objetivos dessa reunião é de extrema importância relacionar que se busca que os entes participantes se apoiem mutuamente, na busca da efetiva proteção dos direitos dos animais.

Avançando um pouco no tempo, em 1988, Bill Clarke, David Favre e Stanley Johnson foram os intelectuais por trás da Convenção Internacional para a Proteção dos Direitos dos Animais (ICPA, em inglês), a qual traz um rol de obrigatoriedades vasto para os entes participantes e delimita muitas facetas desse direito que até então não tinham sido ordenadas.

Entre os pontos primordiais dessa convenção se encontra a definição de que um animal é qualquer mamífero não-humano, pássaro, réptil, anfíbio, peixe ou qualquer outro organismo que possa ser incluído especificamente em um protocolo particular (artigo $2^{\circ}$ ). Em verdade, é de grande evolução para a sociedade internacional possuir um texto que traz a caracterização, com exatidão, desses seres protegidos e aceita e coloca em pauta as peculiaridades existentes no reino animal. A ICPA é a visualização real da dinamização do direito frente às mudanças e anseios sociais regionais e mundiais.

O artigo supracitado é de tamanho valor que se faz necessário incorporá-lo ao presente bojo textual:

O animal em questão deve ser classificado tanto pela sua espécie como pelo ambiente específico em que é encontrado. Para os fins desta Convenção e seus Protocolos, a menos que o contexto exija de outra forma, ou o termo em questão seja definido de outra forma dentro de um Protocolo específico, então o termo: a) "animal" será definido como qualquer mamífero, ave, réptil, anfíbio ou peixe não humano e quaisquer outros organismos que possam ser incluídos especificamente num protocolo específico. b) "animais selvagens": qualquer animal de uma espécie que tenha evoluído como parte do ecossistema local em que se encontra ou que a espécie escapou ao controle humano e estabeleceu uma população reprodutora autossustentável num determinado habitat, ou seja uma espécie que se adaptou à coexistência com os humanos dentro do ambiente urbano. c) "Vida selvagem em cativeiro": qualquer animal de uma categoria de vida selvagem que esteja sob o controle de seres humanos e os animais de gerações subsequentes que tenham nascido desse animal. d) "Animais domésticos" refere-se a espécies que, no contexto da cultura local, têm estado tradicionalmente sob o controle físico, sendo criadas e utilizadas por seres humanos. e) "Animais de companhia", animais de que os seres humanos possuem e controlam em uma utilização primária que não seja em benefício económico. f) "Animais comerciais" refere-se a animais sob o controle de seres humanos com o objetivo principal de ganho econômico ou produção de bens ou serviços. Isso inclui, mas não se limita a animais da fazenda, animais de trabalho, animais de laboratório e animais usados por seres humanos no esporte ou entretenimento. (ICPA, 1988) 
Pela leitura dos dispositivos da convenção pode-se visualizar que uma das preocupações foi criar um sistema de salvaguarda animal de compreensão acessível, em nível mundial. Charlotte E. Blattner destaca a reflexiva frase do Professor Favre: "mas um cavalo é um cavalo, independentemente do país em que vive, e não é apropriado que ele receba alta atenção em alguns lugares e nenhuma preocupação em outras." (FAVRE op. cit. BLATTNER, 2015, p. 22)

Outrossim, os princípios da convenção trazem conceitos expressivos para a matéria do direito animal, colocando em pauta a solidariedade entre espécies vez que afirma que os humanos e os animais coexistem em ecossistemas interdependentes e compartilham uma herança evolutiva. Além disso, os homens como seres morais têm a obrigação de agir de forma responsável para com os não-humanos, considerando também que o valor em tutela é a vida, de forma geral. Por fim, o ser humano possui o dever de providenciar um ambiente favorável e certos cuidados aos animais que controla.

Por último, mas não menos importante, nessa viagem pela evolução do movimento animal, está a Declaração Universal do Bem-Estar Animal, proposta no ano de 2003, na Conferência de Manila e ainda em discussão, sendo que em 2011 foram incorporadas algumas reformas ao texto principal. É imperioso atentar que a referida declaração também milita em favor do princípio da solidariedade entre as espécies, pelo reconhecimento de que os animais são seres sensitivos, de igual forma aos humanos, considerando que todos os seres fazem parte de um único ambiente. O texto também prevê que o animal deve ser encarado por sua parte física e também pelo seu viés psicológico.

\section{A vida permeada pelo direito de solidariedade}

2. 1 BREVE CARACTERIZAÇÃo DOS DIREITOS DE SOLIDARIEDADE E INTEGRALIDAdE DOS PRINCÍPIOS NA ESFERA GLOBAL

O contexto pós $2^{\text {a }}$ Guerra Mundial trouxe consigo diversos questionamentos sobre as relações entre os homens, já muito desgastadas pelos acontecimentos históricos, jurídicos e sociais anteriores, os quais acabaram refletindo, de maior ou menor forma, em cada espaço do globo. É nessa conjuntura de profunda transformação da sociedade que o constitucionalismo contemporâneo se instala e passa a questionar qual seria o fator intrínseco ao relacionamento humano, o qual uniria todos na construção da humanidade.

A ideia de fraternidade/solidariedade inaugura os "direitos de terceira dimensão" e surge como a ligação inerente a qualquer ser humano, justamente pelo respeito à dignidade existente no próprio homem como elo profundo de ajuda mútua e solidificação de direitos garantidos à própria raça humana, tidos como transindividuais, os quais podem ser exemplificados pelo direito ao meio ambiente, à comunicação, ao desenvolvimento, entre outros.

Na esfera do Direito Ambiental, o princípio da solidariedade pode ser traduzido segundo a seguinte acepção:

O princípio da solidariedade aparece, nesse horizonte, como mais uma tentativa histórica de realizar na integralidade o projeto da modernidade, concluindo o ciclo dos três princípios revolucionários: liberdade, igualdade e fraternidade. Trata-se, em última instância, de continuar na edificação de uma comunidade estatal que 
teve o seu marco inicial com o Estado Liberal, alicerçando agora novos pilares constitucionais ajustados à nova realidade social e desafios existenciais postos no espaço histórico-temporal contemporâneo, em especial no tocante à crise ecológica (SARLET; FENSTERSEIFER, 2017, p. 92).

O que se observa, nesse momento, não é apenas a noção de ajuda entre povos, ao contrário, o princípio da solidariedade passa a ser revestido com o manto jurídico. É assim que a solidariedade acabará integrando as cartas constitucionais ao redor do mundo e lançará espectros reflexivos em diversos pontos da vida social, internacional e, principalmente, no campo atual desta pesquisa: o direito ambiental e dos animais.

É importante citar também que a existência dos princípios no ordenamento jurídico ajuda na ponderação da norma a ser aplicada no caso concreto e direciona diversas situações que a regra, por si só, acabaria por não gerar a abstração necessária para a resolução do caso, tendo em vista seu caráter concretista. Posto isso, considerando a força normativa dos princípios de direito e suas consequências práticas, a comunidade internacional passa a ter mais foco neles quando na feitura dos tratados e normas de alcance global (SANDS, 2003, p. 233).

A observação acima destacada leva à constatação de que o conjunto de normas que rodeia o direito internacional com foco na doutrina principiológica foi construído pela comunidade internacional entre membros e não membros do governo, os quais contribuíram com o estudo do alcance prático dos princípios, bem como quanto sua função interpretativa.

Relevante frisar que o direito possui uma posição atual não mais embasada somente no ato de refrear as arbitrariedades estatais ou garantir os direitos sociais, mas se concentra na garantia das prerrogativas essenciais ao homem em toda sua vida na comunidade. Desse modo, chega-se a um ponto da trajetória humana que não basta usufruir dos bens naturais e do trabalho do ser humano em disparada para a conquista mundial, se inaugura, na contemporaneidade, a era da ação limitada do homem pelos princípios de direito, a fim de que a própria humanidade resguarde sua existência, pelo respeito de uns aos outros e, sem dúvidas, pela garantia sustentável de seus recursos com práticas aliadas à essa política.

Nesse contexto, há a possibilidade de discussão dos direitos dos animais/não-humanos, pois se passa a viver em uma sociedade capaz de reconhecer que o homem não é a única forma de vida presente na Terra e que para a construção do futuro será estritamente vital a caracterização e respeito dos direitos dos outros seres. É tempo de se militar em favor da existência como um todo, até porque o direito deve sempre dialogar com a vida.

\subsection{A chegada dos Direitos dos Animais}

Em momento anterior ao início da construção das garantias inerentes aos animais, existia a ideia de que os direitos básicos atribuídos a esses seres adivinham da acepção de meio ambiente devidamente equilibrado que a humanidade possui, o qual proíbe inúmeros abusos contra os animais. Ocorre que essa teoria se encontra, com o tempo, perdendo o sentido, eis que começa a haver o pensamento de que os animais seriam sujeitos de direitos próprios, não mais advindos de uma necessidade de sustentabilidade do homem. 
É permeado pelo diálogo existente entre a norma jurídica em si, suas potencialidades e a vida como um todo que se adquire a abstração necessária para o debate sobre a chegada dos direitos dos animais. Assim, uma exponente parcela dos juristas passa a crer que esses não-humanos estariam protegidos justamente por prerrogativas ligadas à sua própria existência. Veja-se:

\begin{abstract}
Mas, se aprofundarmos nossa reflexão sobre os chamados direitos de personalidade acabaremos por constatar que nada mais são que direitos emanados da pessoa como indivíduo. Devem ser compreendidos, pois, como direitos oriundos da natureza da pessoa como um ente vivo, desde o seu nascimento. Um bebê, antes de ser registrado, já é uma pessoa, pelo menos sob o ponto de vista científico e humano. Valorando a pessoa como um ser vivo temos que reconhecer que a vida não é atributo apenas do homem, e sim um bem genérico, inato e imanente a tudo que vive. E, sob esta ótica a pessoa tem seus direitos imbricados em sua condição de indivíduo, e não apenas pessoa física com identidade civil. Não poderemos chegar a outra conclusão senão a de que os animais, embora não sejam pessoas humanas ou jurídicas, são indivíduos que possuem direitos inatos e aqueles que lhes são conferidos pelas leis, sendo que os primeiros se encontram acima de qualquer condição legislativa. (DIAS, 2016)
\end{abstract}

Segundo a autora acima mencionada, o debate atual seria sobre a valoração da vida como um todo, independente da espécie em questão, afinal, configuraria até mesmo prepotência do homem achar que somente a vida humana é passível de direitos e deveres. Para a construção de um planeta ambientalmente equilibrado, não é necessário apenas proteger minimamente os não-humanos, de modo a criar uma realidade em que possa se produzir muito, sem que se perca a sustentabilidade, é primordial que haja a solidariedade de fato entre as espécies para que haja a sobrevivência daqueles que integram o planeta.

É importante destacar também, nessa etapa do trabalho, o caminho do ganho dos direitos dos animais no globo, pela ótica de um pensador consagrado na temática:

Ainda que as raízes do atual movimento pelos direitos e bem-estar dos animais tenham origem na década de 50, com os esforços de alguns indivíduos para aprovar a lei nacional de proteção aos animais, não foi antes da publicação de Animal Liberation (1977), do Professor Peter Singer, e de A Case for Animal Rights (1983), do Professor Tom Regan, que a reivindicação filosófica pelos direitos dos animais ganhou força e o movimento ganhou respaldo intelectual. (...) Ademais, na década de 80, a organização de ativistas PETA (People for the Ethical Treatment of Animals) e muitas organizações não-governamentais foram criadas. Isso deu início ao movimento social e jurídico para conscientizar sobre o sofrimento animal e promover mudanças dentro do sistema jurídico em favor dos animais. Esse movimento crescente teve uma atividade considerável e interessou a população em geral, desembocando, no verão de 1990, na "March for the Animals" em Washington D.C., (nossa capital federal). Mais de 10.000 pessoas marcharam da Casa Branca (residência do presidente dos EUA) até o prédio do Congresso Nacional, entoando palavras de ordem e proferindo discursos em benefício dos animais. O itinerário e o formato da marcha seguiram as antigas tradições das marchas de protesto popular, criadas durante o movimento pelos direitos civis nos Estados Unidos nos anos 60 (FAVRE, 2006). 
O professor David Favre demonstra, no artigo do qual o excerto acima foi retirado, a trajetória do ganho de força dos direitos dos animais, especialmente nos Estados Unidos. Foram os crescentes trabalhos sobre o tema, as movimentações populares e o ativismo de vários pensadores da problemática que repercutiram na solidificação de uma mentalidade voltada às garantias ambientais, principalmente devido ao intenso debate realizado pelas faculdades de direito americanas, com a exposição de trabalhos e até mesmo inserção da disciplina "direitos dos animais" na grade curricular dos cursos jurídicos, como explicitado pelo autor:

\begin{abstract}
Além dos tribunais e do parlamento, as instituições jurídicas incluem faculdades de direito, revistas jurídicas, e as várias associações de advogados e de professores de direito. Qual é a visibilidade e a credibilidade da temática animal nessas instituições? Se não houver o progresso em todos os setores da comunidade jurídica, o sucesso da proteção dos animais não será possível. Nós, nos Estados Unidos, temos progredido, particularmente, nos últimos dez anos, mas ainda há muito por fazer. Ao mapear o progresso e a sua falta, nos Estados Unidos, os leitores brasileiros e de outros países terão algumas referências para que possam avaliar o progresso da questão dos direitos e do bem-estar dos animais dentro de seus próprios países.
\end{abstract}

(FAVRE, 2006)

É por meio da discussão constante nos órgãos nacionais, escolas, faculdades, mídia e organismos internacionais que a posição ocupada pelo assunto ganhou novos traços na atualidade. É impensável nos dias de hoje não se deparar com situações fáticas e jurídicas que precisam da tutela do direito na seara animal. Nesse contexto, pode-se inserir o debate sobre o evento no Brasil denominado "vaquejada", motivo de confecção da Emenda Constitucional n. 96/2017 que passou a não considerar crueis as práticas desportivas que utilizam animais, desde que sejam manifestações culturais, de modo que tais venham a ser legisladas e passem também a assegurar o bem-estar dos animais envolvidos.

Ressalta-se que a legislação acima mencionada foi promulgada a fim de superar a decisão do Supremo Tribunal Federal, do ano de 2016, momento em que foi declarado inconstitucional o evento da "vaquejada". Assim, pode-se perceber que ainda há visões e decisões conflitantes sobre o assunto, existentes no mesmo ordenamento jurídico, as quais são passíveis de mudanças ao longo do tempo, pois novos casos surgem para julgamento e dependendo da situação fática e jurídica existente, o posicionamento adotado pode ser diferente.

É justamente por intermédio dessas indagações feitas pela sociedade aos entes jurídicos, para resolução de situações atinentes à vida cotidiana, que se encontra a relevância da tese afirmada por este artigo. Ou seja, as problemáticas só conseguirão ser resolvidas quando for colocado em pauta que o animal é um ser vivo que possui direitos próprios, como os humanos, sendo que estes devem militar para a segurança desses direitos na comunidade local, a fim de que seja possível a sustentabilidade de fato do planeta. 
3 Os NÃo-humanos e A SOCIEdAde ATUAL: CONSTRUÇÃo da SOlidariedade

\subsection{Os desafios na tUtela ambiental}

Ainda há, na atualidade, diversas situações em que o direito ambiental deve ser garantia de proteção ao menos parcial das prerrogativas inerentes aos seres vivos, de forma a resguardar não somente um meio ambiente equilibrado e sustentável, mas também a convivência harmônica e não degradante entre as espécies.

É por esta razão que a solidariedade entre as espécies se coloca em pauta e leva a desdobramentos que antes eram pouco relacionados pela abstração humana. Os animais possuem sensibilidade aos aspectos do ambiente, principalmente as condições de vida em que são submetidos, já que muitas vezes o homem é responsável por sua mudança de habitat e degradação de seu ambiente natural, a fim de buscar o progresso tão almejado.

No entanto, pelo fato de que os animais, frequentemente, são pouco considerados em meio a busca implacável do desenvolvimento humano, há paulatina desconsideração de características inerentes aos seres vivos, como: a sensibilidade a dor, aos maus-tratos, a confinação, as experiências constantes, as apresentações artísticas exploratórias, entre outras. Aliado ao mencionado está o pensamento abaixo:

Para chegarmos a esse entendimento precisamos ultrapassar a concepção do sujeito cartesiano, filho da razão, capaz de distinguir o bem do mal. Mais do que um ser racional o homem é um ser moral, como diz Kant. Qualquer tentativa de estabelecer uma ligação entre a razão e a ética não consegue sustentar-se. A questão aqui não é saber se somos capazes de falar ou de raciocinar, de legislar e assumir deveres, mas se somos passíveis de sofrimento, se somos seres sensíveis. Nesta hipótese a capacidade de sofrimento e de ter sentimento são as características vitais que conferem, a um ser, o direito à igual consideração. $\mathrm{O}$ fato de o homem ser juridicamente capaz de assumir deveres em contraposição a seus direitos, e inclusive de possuir deveres em relação aos animais, não pode servir de argumento para negar que os animais possam ser sujeitos de direito. É justamente o fato dos animais serem objeto de nossos deveres que os fazem sujeitos de direito, que devem ser tutelados pelos homens.

(DIAS, 2016)

Em razão dessa acepção é que cresce a noção de solidariedade entre espécies na construção de um cenário favorável ao desenvolvimento de todos os seres vivos. Observa-se:

No plano jurídico, à luz das considerações já desenvolvidas, a vedação das práticas crueis contra os animais (não humanos), conforme estabelecido no art. 225, § $1^{\circ}$, VII, da CF/88, e no art. 32 da Lei dos Crimes e Infrações Administrativas Ambientais (Lei n. 9.605/98), reforça a concepção de um princípio de solidariedade entre as espécies naturais. Não apenas em relação aos animais, mas à Natureza em termos gerais. A ideia de "solidariedade entre espécies naturais", portanto, também pode transportar o reconhecimento do valor intrínseco de todas as manifestações existenciais, bem como o respeito e a reciprocidade indispensável ao convívio harmonioso entre todos os seres vivos na nossa casa planetária comum. A proposta de um contrato natural, conforme formulada por Serres, teria como propósito justamente ampliar o atual pacto social, incluindo novos parceiros de aventura natural no rol dos sujeitos de direito. O princípio da solidariedade passa a ser uma das bases-éticas (e jurídicas) fundamentais da sociedade contemporânea na sua caminhada civi- 
lizatória, considerando todas as suas dimensões (intrageracional, intergeracional e interespécies) (SARLET; FENSTERSEIFER, 2017)

O desafio contemporâneo da tutela ambiental está em integrar os conceitos acima demonstrados primeiramente na sociedade que é de onde o direito se espelha para efetuar suas constantes mudanças e atualizações. Em seguida, como o Professor Favre mesmo havia mencionado é extremamente relevante que a discussão permeie as instituições jurídicas ao redor do globo, pois sem o debate na comunidade acadêmica se torna mais difícil a produção científica sobre o assunto e consequentemente a pouca demonstração sobre o tema para a comunidade em geral.

Ademais, é tempo de mudança de mentalidade não apenas no tratamento jurídico conferido a esses seres, mas também na percepção humana que se deve ter a fim de efetivar o cuidado de que os animais necessitam e que está proclamado no preâmbulo da Declaração Universal dos Direitos dos Animais (1978):

Considerando que todo o animal possui direitos; Considerando que o desconhecimento e o desprezo desses direitos têm levado e continuam a levar o homem a cometer crimes contra os animais e contra a natureza; Considerando que o reconhecimento pela espécie humana do direito à existência das outras espécies animais constitui o fundamento da coexistência das outras espécies no mundo; Considerando que os genocídios são perpetrados pelo homem e há o perigo de continuar a perpetrar outros; Considerando que o respeito dos homens pelos animais está ligado ao respeito dos homens pelo seu semelhante; Considerando que a educação deve ensinar desde a infância a observar, a compreender, a respeitar e a amar os animais (...). (DECLARAÇÃO UNIVERSAL DOS DIREITOS DOS ANIMAIS, 1978)

Dessa forma, observa-se que a própria declaração assevera a existência do princípio da solidariedade entre as espécies quando menciona: "Considerando que o reconhecimento pela espécie humana do direito à existência das outras espécies animais constitui o fundamento da coexistência das outras espécies no mundo". É essa solidariedade presente entre as diversas formas de vida que assegura a vivência do homem no planeta Terra justamente porque todas as espécies são responsáveis, de alguma forma, pela manutenção da existência tal como ela é, por isso se permanece a cadeia alimentar, os pássaros polinizadores de flores, as abelhas produtoras de mel, porque a presença de cada ser é necessária também ao desfrute do planeta.

\subsection{NOVO PANORAMA DOS DIREITOS DOS ANIMAIS}

É embalado por toda essa análise principiológica e social dos direitos dos animais que é possível asseverar que a era da afirmação dos direitos desses seres chegou. É por meio da solidariedade presente nas esferas da sociedade que será possível implementar tais prerrogativas inerentes a esses seres. 
A pergunta principal nesse contexto é o que vem a caracterizar um ser passível de direitos na era atual? A sua concepção humana? A vida em sua acepção básica? Ou outro fator ligado ao desenvolvimento e potencialidades de cada espécie? A resposta deveria ser que os direitos se baseariam na garantia da vida, não importando a forma que ela se apresenta ao mundo exterior.

Reificar os animais, ou seja, tratá-los como propriedade, já foi uma característica presente na humanidade em tempos antigos, usavam-se os não-humanos como instrumentos da vontade humana, seja para atender suas necessidades de mobilidade ou de vaidade e alimentação. Foi com o passar do tempo e a mudança na ideia de tratamento devido aos animais que se pode configurá-los como uma espécie passível de direitos.

Não obstante, as instituições formadoras de opinião têm maior participação nessa transformação intelectual:

\begin{abstract}
Onde está o Brasil nesse caminho em direção a mudança? A existência da revista em que você está lendo este artigo é por si mesma um sinal de progresso. O Brasil tem uma organização nacional de advogados focalizando a temática jurídica animal? $\mathrm{O}$ assunto tem sido considerado nas faculdades de Direito? Tem sido essas leis divulgadas pela imprensa em geral? Existe algum professor, de dedicação exclusiva em uma Universidade, que dedique seus esforços acadêmicos em benefício da questão animal? Todas essas coisas são etapas no processo de assimilação das ideias pela sociedade em geral. Etapas para medir o progresso do status jurídico dos animais. Quando existirá uma ampla conscientização do público em geral sobre a necessidade de mudança, a qual não acontecerá sem a integração dessas questões dentro das instituições jurídicas da nação. Eu espero continuar ouvindo relatos positivos do Brasil como os do ano passado. (FAVRE, 2006)
\end{abstract}

Pelo exposto, nota-se a dinâmica da expansão do direito dos animais o que remete a um panorama mais afirmativo da proteção e caracterização definitiva de seus direitos como seres detentores de valor.

Portanto, demonstra-se a vivência em uma era de direitos mais que dinâmicos, sendo ferramentas de transformação da realidade nacional e internacional. $\mathrm{O}$ avanço do homem em diversos meios fez com que também fosse imprescindível a mudança de conceitos sobre a relação entre as espécies.

\title{
CONCLUSÃo
}

Em épocas passadas, tratar os animais ou qualquer outro ser vivo que integrasse a natureza com respeito aos seus direitos inerentes era percebido pela sociedade como algo impensável ou senão um retrocesso.

Desde quando o homem passou a moldar o meio ambiente de acordo com aquilo que lhe traria maiores benefícios que a utilização dos animais como ferramentas de transporte, alimento, entretenimento (por meio de apresentações ao público), experiências, entre outras funções, passou a ser regra básica do progresso humano. 
Entretanto, com o desenvolvimento jurídico e maior problematização das questões sociais e jurídicas que circundam a sociedade foi que se chegou ao debate acerca dos direitos dos animais frente aos abusos e arbitrariedades humanas, pautando-se, ainda pela forte proteção ambiental instaurada.

É necessário crer que esses direitos não devam ser assegurados somente tendo em busca a noção de sustentabilidade atual. Apesar dos animais não possuírem o mesmo nível de intelecção e comunicação que o homem, não é por isso que não necessitam ter um tratamento digno e até mesmo justo quando nas questões jurídicas que são circundados.

Não é mais possível não falar ou mencionar o tema, desde conversas informais nas quais o assunto pode ser o teste de cosméticos em animais, o uso indiscriminado desses seres em espetáculos, a transmissão ou não da febre amarela pelos macacos, até as discussões acadêmicas, como a questão da legalidade do transporte de animais vivos destinados para outros países. A temática é mais do que atual, é necessário se debater agora para prevenir eventuais degradações e injustiças futuras.

O presente artigo abordou, de maneira sucinta, a ligação que se pode observar entre o princípio da solidariedade que liga a humanidade em sua primazia, em busca da garantia de prerrogativas transindividuais, e o direito dos animais. É esse sentimento de preservação mútua existente entre os seres humanos que deve se unir ao caminho pela efetivação dos direitos dos animais.

Dessa forma, haveria o pensamento primordial do valor da vida, independentemente de qual forma ela assume na Terra. Todos os seres possuem importância na manutenção do planeta e por essa razão precisam ter a salvaguarda de seus direitos.

São seres que sentem dor, fome, frio, calor, pressões do ambiente, têm de fugir de predadores, mudar de habitat quando o seu é degradado por algum fator, principalmente pela ação humana que leva às mudanças climáticas e de padrões ambientais. Essas características os aproximam do ser humano na medida em que o homem compartilha da mesma natureza.

Aliado a isso, o trabalho também apresenta o panorama do direito de solidariedade e do direito dos animais por pontos de vistas de autores relevantes, traçando um progresso lógico e conciso dessas ideias.

Assim, há a construção de um novo panorama no direito ambiental no qual não deve haver unicamente a proteção da ordem natural, com freio às atitudes humanas impensadas e danosas, mas também o apreço por outras formas de vida e luta pela proteção de seus direitos enquanto seres integrantes do planeta Terra.

\section{REFERÊNCIAS}

BRASIL. Recurso Especial n. ${ }^{\circ}$ 153531-8 (Supremo Tribunal Federal 03 de junho de 1997).

.Emenda constitucional no 96, de 6 de junho de 2017. (s.d.). Disponível em: http:/ / www.planalto.gov.br/ccivil_03/constituicao/emendas/emc/emc96.htm Acesso em 05 de janeiro 2018.

.Instituto Brasileiro do Meio Ambiente e dos Recursos Naturais Renováveis. IBAMA. Convenção sobre Comércio Internacional das Espécies da Flora e Fauna Selvagens em Perigo de Extinção (Cites). Disponível em: http://www.ibama.gov.br/cites-e-comercio-exterior/cites Acesso em: 20 de abril de 2018. 
BLATTNER, C E. Global Animal Law: Hope beyond Illusion: The Potential and Potential Limits ofInternational Law in Regulating Animal Matters. Mid-Atlantic Journal of Law E Public Policy. Vol. 3:1, 2015. p.10-54.

CAMATTA, AFA; SOUZA, LMCG; ARRUDA JÚNIOR, P. Ineficiência das convenções internacionais no que tange ao papel dos estados na proteção dos animais selvagens em razão da diminuição constante das espécies. Revista do Programa de Pós-Graduação em Direito da UFC. v. 34.2, jul./ dez. 2014. p.29-51.

CONVENTION ON INTERNATIONAL TRADE IN ENDANGERED SPECIES OF WILD FAUNA AND FLORA. CITES. Disponivel em: https://www.cites.org/eng/disc/what.php. Acesso em 06 de abril de 2018.

DECLARAÇÃO UNIVERSAL DOS DIREITOS DOS ANIMAIS. (27 de janeiro de 1978). Bélgica, Bruxelas. Disponível em http://www.urca.br/ceua/arquivos/Os\%20direitos\%20dos\%20animais\%20UNESCO. pdf Acesso em 15 de janeiro de 2018.

DIAS, E. C. Os animais como sujeitos de direito. Direito Animal, 2006. p.119-121. Disponível em : https:// bdjur.stj.jus.br/jspui/bitstream/2011/104270/animais_sujeitos_direito_dias.pdf Acesso em 04 de fevereiro de 2018.

FRANCIONE, G L. Animal Rights and Animal Welfare. Rutgers Law Review. v.48, 1996. p.397-469.

FAVRE, D. O ganho de força dos direitos dos animais. Direito Animal, 2006. Disponível em: https:/ / portalseer.ufba.br/index.php/RBDA/article/viewFile/10239/7295. Acesso em 10 de janeiro de 2018.

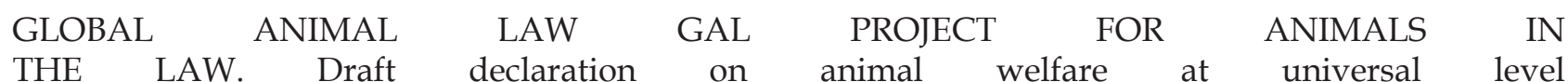
udaw proposal.. Universal declaration on animal welfare (udaw). Disponível em: https://www. globalanimallaw.org/database/universal.html. Acesso em:04 de março de 2018.

INTERNATIONAL CONVENTION FOR THE PROTECTION OF ANIMALS. Proposed by the Committee for the Convention for the Protection of Animals. Abril, 1988. Michigan State University. Animal Legal \& Historical Center. Disponível em: https://www.animallaw.info/treaty/international-convention-protection-animals. Acesso em: 05 de maio de 2018.

PORTAL DE PESQUISAS TEMÁTICAS E EDUCACIONAIS. Organizações Internacionais. Disponível em: https://www.suapesquisa.com/geografia/organizacoes_internacionais.htm. Acesso em 05 de abril de 2018.

POSNER, R A. Animal Rights. The Yale Law Journal, v.110. 2000. p.527-541.

RESENDE, P. Donos já podem registrar animais de estimação em cartório de Goiânia. (s.d.). Disponível em https:/ /g1.globo.com/goias/noticia/donos-ja-podem-registrar-animais-de-estimacao-em-cartorio-de-goiania.ghtml Acesso em 06 de fevereiro de 2018.

SANDS, P. Principles of Internacional Environmental Law (2 ${ }^{\mathrm{a}}$ Edição ed.). New York: Cambridge University Press. 2003.

SARLET, I. W.; FENSTERSEIFER, T. Princípios do Direito Ambiental (2 ${ }^{a}$ Edição ed.). São Paulo, Brasil: Saraiva. 2017. 